\title{
Substrate for Cross-Talk Inhibition between Thalamic Barreloids
}

\author{
Barthélémy Desîlets-Roy, Caroline Varga, Philippe Lavallée, and Martin Deschênes \\ Centre de Recherche, Université Laval-Robert Giffard, Hôpital Robert-Giffard, Québec G1J 2G3, Canada
}

A double-labeling protocol was used to determine whether thalamocortical and reticular thalamic cells with overlapping receptive fields form open or closed loop connections in the vibrissal system of the rat. Results show that individual reticular cells exclusively project to the barreloid representing the principal whisker of their receptive field. Furthermore, solid retrograde labeling of relay cells reveals that a large number extend dendrites outside their home barreloid. This feature, together with previous demonstrations that reticular thalamic axons principally contact the dendrites of relay cells, provide a morphological substrate for cross-talk inhibition between thalamic barreloids.

Key words: barrels; barreloids; whisker; vibrissa; reticular thalamic nucleus; thalamic relay cells
The nucleus reticularis thalami (nRT) occupies a key position in the thalamocortical circuitry. It receives excitatory inputs from thalamocortical and corticothalamic axons, and it returns inhibitory projections to the thalamic relay cells. This inhibitory action is potent and can significantly modify the rate and pattern of relay cell discharges (Steriade et al., 1985; Lee et al., 1994; Hartings and Simons, 2000). A central issue about the nRT network is whether the constituent cells inhibit the relay cells from which they receive input or whether they inhibit other pools of relay neurons. However, these two possibilities are not mutually exclusive, and there exists anatomical and electrophysiological evidence supporting both (Shosaku, 1986; Bal et al., 1990; Brumberg et al., 1996; Crabtree et al., 1998; Pinault and Deschênes, 1998a). In the present study we directly addressed this question by taking advantage of the highly segregated organization of the rodent vibrissal system.

From periphery to cortex this system is made of discrete cellular aggregates that replicate the arrangement of the vibrissae on the mystacial pad. In the ventral posterior medial (VPM) nucleus of the thalamus, whisker-related modules are called barreloids, and each barreloid projects onto a corresponding module, called barrel, in the primary somatosensory cortex. Thus, on the one hand, the architecture of a single barreloid can be outlined by the injection of a retrograde tracer in its related barrel (Hoogland et al., 1987; Land et al., 1995; Pierret et al., 2000). On the other hand, it is well established that nRT and VPM cells have receptive fields composed of one principal and several surrounding whiskers (Simons and Carvell, 1989; Armstrong-James and Callahan, 1991; Diamond et al., 1992). Responses to surrounding whiskers are strongly depressed by anesthetics, which reduce the receptive field size of VPM and nRT cells to the principal whisker (Freidberg et al., 1999). Thus, under deep anesthesia the response of nRT cells to principal whisker deflection ought to be relayed by the barreloids cells responding to the very same

Received Jan. 10, 2002; revised Feb. 12, 2002; accepted Feb. 14, 2002.

This work was supported by Grant MT-5877 from the Canadian Institutes of Health Research (M.D.) and by a Conseil de la Recherche en Sciences Naturelles et Génie du Canada fellowship (C.V.).

Correspondence should be addressed to Dr. Martin Deschênes, Center de Recherche, Université Laval-Robert Giffard, 2601 de la Canardière, Québec City, Canada G1J 2G3. E-mail: martind@microtec.net.

Copyright (C) 2002 Society for Neuroscience $0270-6474 / 02 / 220001-05 \$ 15.00 / 0$ vibrissa. On the basis of these data, a double-labeling protocol was used to determine whether nRT cells form closed or open loop connections with their thalamic targets. A thalamic barreloid was retrogradely labeled by injecting Fluoro-Gold (FG) in an identified barrel column, and the axon of single nRT cells responding to the same whisker, or to an adjacent whisker located on the same arc, was anterogradely labeled by juxtacellular application of biotinylated dextran amine (BDA).

\section{MATERIALS AND METHODS}

Experiments were performed in 30 adult rats (Sprague Dawley , 250-300 $\mathrm{gm})$ in accordance with federally prescribed animal care and use guidelines. The University Committee for Animal Use in Research approved all experimental protocols. First, rats were anesthetized with a mixture of ketamine $(75 \mathrm{mg} / \mathrm{kg})$ plus xylazine $(5 \mathrm{mg} / \mathrm{kg})$, and a barrel column, usually $\mathrm{C} 2$ or $\mathrm{D} 2$, was located by recording unit responses to manual whisker deflection. Then, a micropipette (tip diameter, $\sim 6 \mu \mathrm{m}$ ) containing FG (2\% in $0.1 \mathrm{M}$ cacodylate buffer, $\mathrm{pH} 7.0$; Fluorochrome, Inc., Denver, CO) was lowered in layer 4 (depth, $740 \mu \mathrm{m}$ ) of the identified barrel column. The tracer was ejected with positive current pulses of 100 $\mathrm{nA}$ for $10 \mathrm{~min}$. After completing this protocol in both hemispheres, the skin was sutured, rats were given analgesics (Anafen; $5 \mathrm{mg} / \mathrm{kg}$ ), and they were returned to the animal facilities. Twenty-four to $48 \mathrm{hr}$ later animals were reanesthetized with ketamine-xylazine, and we searched for nRT cells that responded to the whisker whose barreloid had been retrogradely labeled with FG. Extracellular recordings were made with fine micropipettes (diameter, $0.5-1 \mu \mathrm{m})$ filled with K-acetate $(0.5 \mathrm{M})$ and low molecular weight BDA (2\% BDA, $3 \mathrm{kDa}$; Molecular Probes, Eugene, OR). Throughout the experiments a deep level of anesthesia was maintained so that nRT, as well as VPM cells, responded to only one whisker. Once a responsive nRT unit had been isolated, it was labeled juxtacellularly by the application of positive current pulses $(2-8 \mathrm{nA} ; 200 \mathrm{msec}$ duration; 50\% duty cycle) for $\sim 10$ min (Pinault, 1996). In most cases, only one cell was stained in each thalamus, and animals survived $2-3 \mathrm{hr}$

This article is published in The Journal of Neuroscience, Rapid Communications Section, which publishes brief, peerreviewed papers online, not in print. Rapid Communications are posted online approximately one month earlier than they would appear if printed. They are listed in the Table of Contents of the next open issue of JNeurosci. Cite this article as: JNeurosci, 2002, 22:RC218 (1-4). The publication date is the date of posting online at www.jneurosci.org.

http://www.jneurosci.org/cgi/content/full/6338 
after the last injection. They were perfused under deep anesthesia with saline followed by a fixative containing $4 \%$ paraformaldehyde and $0.5 \%$ glutaraldehyde in phosphate buffer (PB; $0.1 \mathrm{M}, \mathrm{pH} 7.4)$. Brains were removed, post-fixed overnight in the same fixative, and cut coronally at 70 $\mu \mathrm{m}$ with a vibratome. After three washes in PBS (0.01 M, pH 7.4) sections were treated for $30 \mathrm{~min}$ with a solution of $50 \%$ ethanol plus $1 \%$ hydrogen peroxide. They were rinsed several times in PBS, and preincubated for 1 hr in PBS with 3\% normal goat serum and $0.2 \%$ Triton X-100. They were then incubated overnight in the same medium containing an anti-FluoroGold antiserum (1:8000; Chemicon, Temecula, CA). The antibody was then revealed using a peroxidase-labeled secondary antibody (goat IgG; Chemicon) and 3,3'diaminobenzidine tetrahydrochloride (DAB) as a substrate (brown reaction product). Next, sections were processed for BDA histochemistry using the ABC kit (Vector Laboratories, Burlingame, CA) and nickel-DAB (black reaction product). Finally sections were mounted on gelatin-coated slides, dehydrated in alcohols, cleared in toluene, and coverslipped without counterstaining. Labeled material was drawn with a camera lucida using a $40 \times$ objective.

In five rats we attempted to get solid retrograde labeling of barreloid cells by injecting FG with larger currents (up to $300 \mathrm{nA}$ ), by allowing a longer survival period (4 days), and using a more sensitive immunohistochemical method. In these experiments FG was revealed with a biotinylated secondary antibody (Vector Laboratories), the $\mathrm{ABC}$ reaction, and Ni-DAB as a chromogen. Two of 10 injection sites resulted in the solid labeling of a single barreloid, whereas the labeling of multiple barreloids or cellular degeneration was observed in the other cases.

\section{RESULTS}

Fluoro-Gold injections of the size shown in Figure $1 a$ led to the retrograde labeling of single barreloids in $\sim 50 \%$ of the cases. When two barreloids were backfilled, one usually contained less darkly stained somata so that the border between the two arrays remained clearly discernible. Otherwise, data were discarded. Like the barreloids outlined by cytochrome oxidase staining (Land et al., 1995), retrogradely stained cells form a narrow array, $\sim 100$ - $\mu \mathrm{m}$-wide, that extends from the VPM-posterior group border toward the ventral posterior lateral nucleus.

Reticular thalamic cells that respond to whisker deflection are found in the central tier of the dorsal sector of the nucleus, 2.5-3.0 mm behind the bregma. Their distribution is somatotopically organized (Shosaku et al., 1984), the E and A rowresponsive cells lying in the anterior and posterior pole, respectively. Arcs are represented dorsoventrally, so that in a typical descent D1-, D2-, D3-, etc. responsive cells are found in succession.

Our database comprises 24 nRT cells that exclusively responded to the motion of the vibrissa whose barreloid had been retrogradely labeled $(n=16)$ or to the deflection of an adjacent vibrissa situated on the same $\operatorname{arc}(n=8)$. Axons were sufficiently stained to be traced to their termination site and to ensure that no main branches escape detection. Results leave little ambiguity; all stained nRT cells project to, and only to, the barreloid representing the principal whisker of their receptive field (Fig. 1c). Three projection patterns were found (Fig. 2): some nRT axons $(n=$ 5 ) only distribute terminals in the dorsalmost segment of the barreloid that abuts on the posterior group, some $(n=12)$ innervate the rest of the barreloid with few terminations in the dorsal segment, and the others $(n=7)$ give off terminations throughout the whole barreloid. Otherwise cells giving rise to the three types of terminal fields could not be further distinguished on the basis of their location or somatodendritic morphology. Thus, these results clearly demonstrate that nRT and VPM cells that respond to the same principal whisker do form closed loop connections.

A network of lateral inhibition cannot be excluded, however, because a number of VPM cells have dendritic arbors that are wider than the size of a barreloid (Chiaia et al., 1991; Ohara and
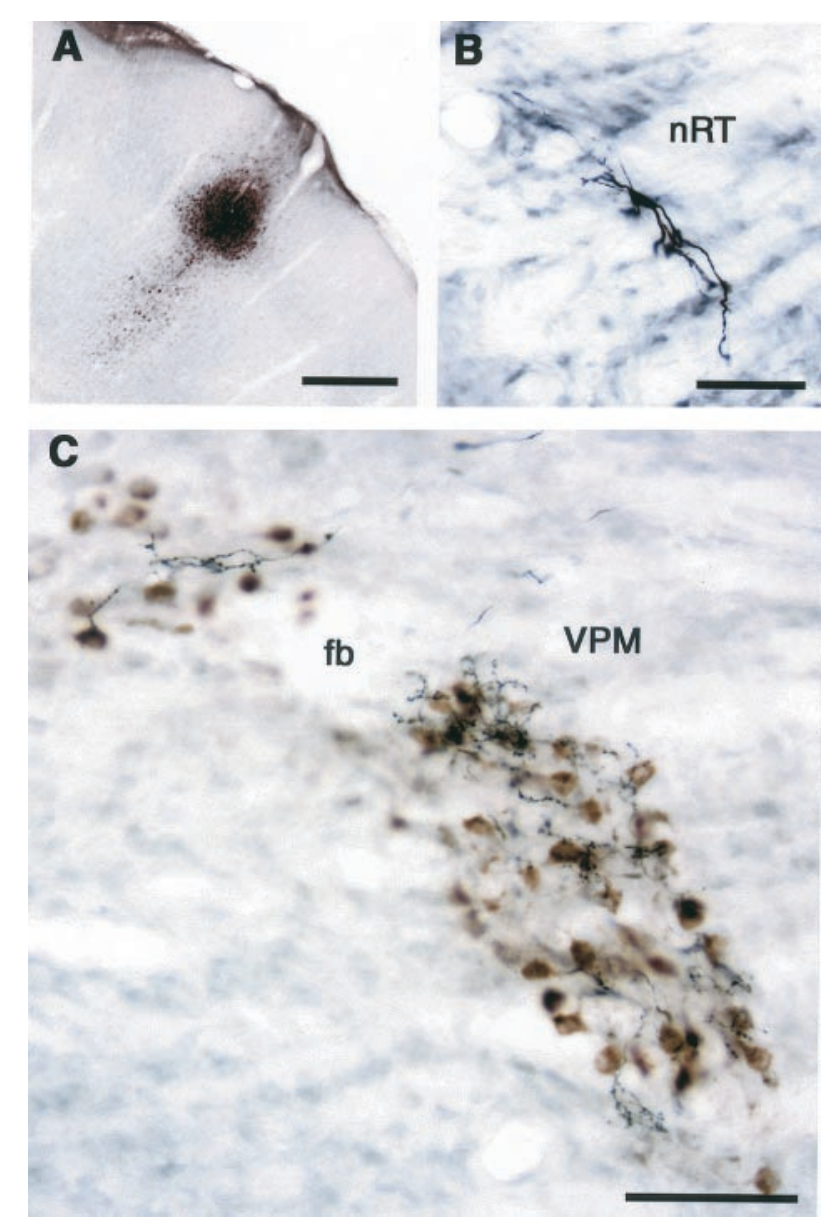

Figure 1. Terminal field of an nRT cell into a thalamic barreloid. Relay cells forming the D2 barreloid were backfilled after an FG injection into the D2 barrel column $(a)$, and an nRT cell that responded to deflection of the same vibrissa was juxtacellularly stained with BDA $(b)$. Note the precise overlap of terminations with the array of labeled somata $(c)$. Scale bars: $a, 500 \mu \mathrm{m} ; b, c, 100 \mu \mathrm{m}$. $f b$, Fiber bundle.

Havton, 1994; Zantua et al., 1996). Although no morphometric study has yet quantified the relative importance of these "extrabarreloid dendrites", the solid retrograde labeling of barreloid cells highlights their large number (Fig. 3). Because electronmicroscopic studies have clearly established that nRT axons distribute contacts throughout the dendritic arbor of thalamic relay cells (Peschanski et al., 1983; De Biasi et al., 1988; Cucchiaro et al., 1991; Liu et al., 1995), extrabarreloid dendrites ought to receive synaptic contacts from the nRT cells that project to the barreloid they invade. Thus from a strict anatomical viewpoint, an nRT cell should exert both recurrent inhibition on cells that relay input from its principal whisker and simultaneously impose remote lateral inhibition onto the relay cells principally excited by an adjacent whisker.

\section{DISCUSSION}

The present study revealed a point to point relationship between $\mathrm{nRT}$ and barreloids cells with receptive fields dominated by the same principal whisker. Reticular cells either form small compact terminal fields in the dorsalmost part of the barreloids or more extensive fields filling a large expanse of the barreloid. We were unable, however, to label any nRT cell with diff use axonal arbors in the VPM. By using the whole-cell recording and labeling 


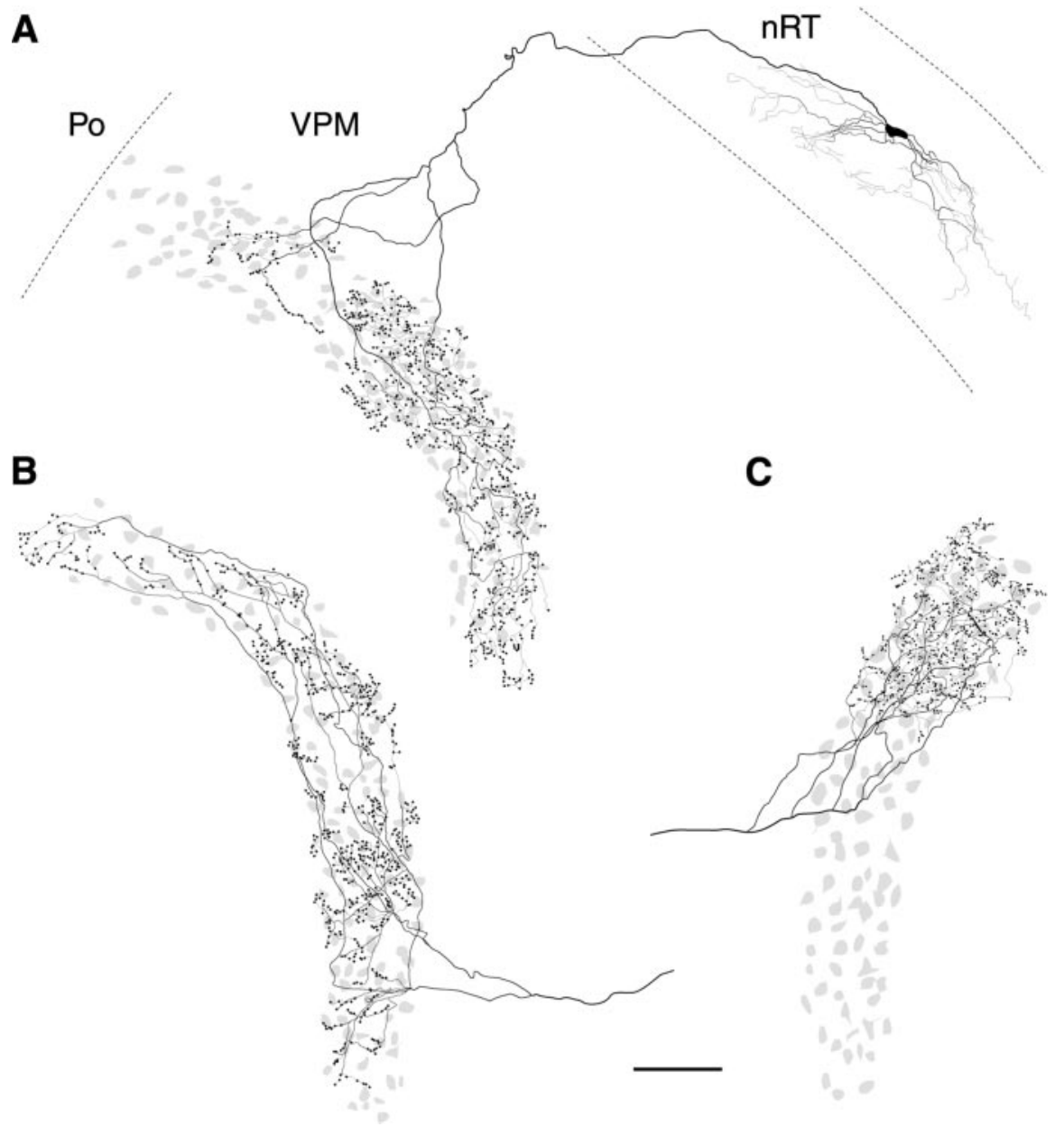

Figure 2. Projection patterns of individual reticular axons in thalamic barreloids. Arrays of retrogradely labeled cell bodies that correspond to the barreloids $\mathrm{D} 2(A), \mathrm{B} 3(B)$, and $\mathrm{C} 2(C)$ are mapped in gray tone in the background. Terminal fields of nRT cells either distribute in different segments $(A, C)$ or across the whole extent of a barreloid (B). Scale bar, $100 \mu \mathrm{m}$. technique in thalamic slices of young rats (10- to 15-d-old), Cox et al. (1996) identified three types of nRT arbors in the VPM, ranging from diff use to compact. Their "cluster and intermediate types" likely correspond to the patterns we found, but the "diff use type", which contained a low density of axonal swellings, might be representative of an immature stage of development because similar diff use and extensive nRT terminal fields are commonly observed in Golgi material obtained from young rodents (1- to 20-d-old; Scheibel and Scheibel, 1966). This is keeping with the delayed maturation of relay cells that acquire their adult form only by P21 in rodents (Zantua et al., 1996; Warren and Jones, 1997). Still, the possibility remains that we missed the diff use type because these nRT cells do not respond to whisker motion in anesthetized animals. The same qualification applies to the possibility that some nRT cells may project to both, the barreloids and the posterior group, although the labeling of over 127 individual nRT cells in adult rats never revealed such projection pattern (Pinault and Deschênes, 1998b). Together, these results suggest that the nRT-mediated internuclear inhibition that has been disclosed between cells of the VPM and posterior group in slices (Crabtree et al., 1998) likely relies on patterns of axonal convergence within the nRT itself. Given the highly segregated organization of the vibrissal system, it would be premature to consider the present results as a model for the synaptic organization of other thalamic nuclei in rat or in other species. Different thalamic subsystems evolved to process different types of sensory inputs, and may therefore differ in the details of their internal circuitry.

\section{Physiological significance}

The innervation of the dorsalmost part of barreloids by a distinct group of $\mathrm{nRT}$ axons points to a functional specialization of this region. This region also stains more densely for cytochrome oxidase (Land et al., 1994; Pierret et al., 2000), receives trigeminal input from large-sized principalis cells having mutiwhisker-receptive fields (Veinante and Deschênes, 1999), and contains a larger density of labeled cells after retrograde tracer injection in layer 6 of the barrel field (Land et al., 1994). No physiological study has yet reported distinct response properties for cells located dorsally in barreloids, but the specificity of connections suggests a parallel stream of vibrissal information processing.

In agreement with the present results, cross-correlation analysis of activities simultaneously recorded from vibrissa-responsive neurons in the nRT and VPM in urethane-anesthetized rats revealed that both excitatory and inhibitory interactions are restricted to neurons with receptive field on the same vibrissa (Shosaku, 1986). Adjacent whisker-evoked inhibition of VPM cells in fentanyl-sedated rats was also reported to be weak or absent (Brumberg et al., 1996). Our results provide morphological substrate for these observations, but they also raise the possibility of subtle cross-whisker inhibitory interactions that may not be detectable with single-unit recordings. Indeed, the spread of VPM cells dendritic arbors in adjacent barreloids raises the possibility that surround inhibition acts distally in the dendrites. Remote cross-whisker inhibition might only modestly depress the 


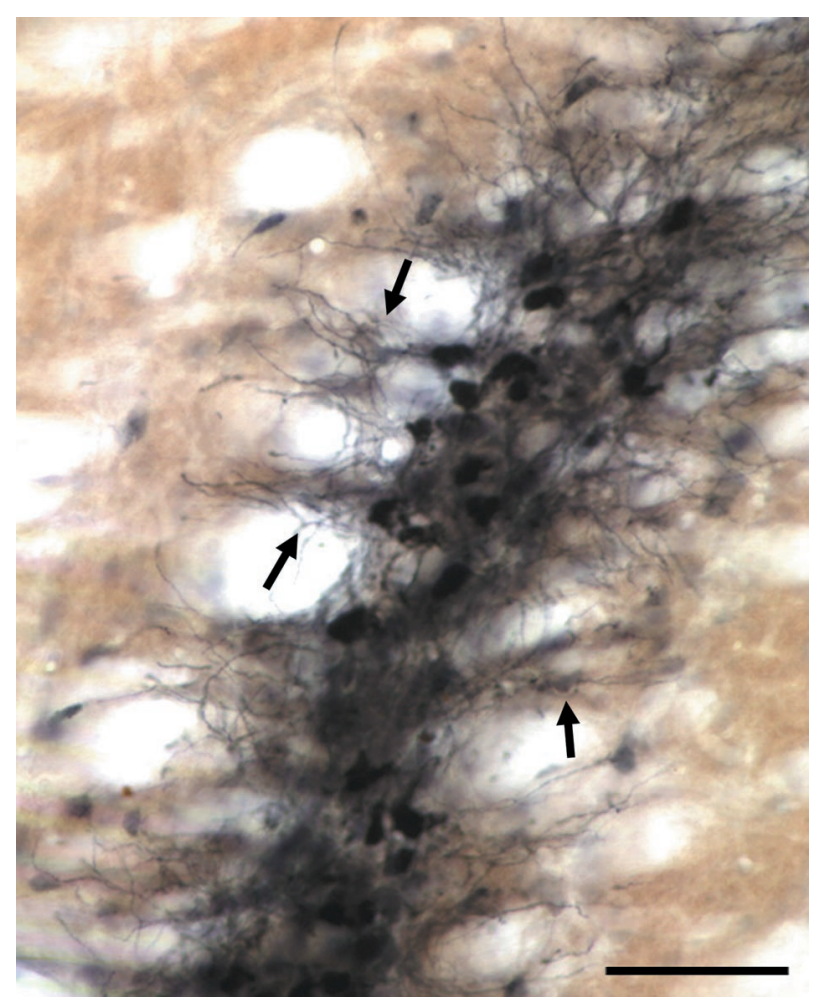

Figure 3. Solid retrograde labeling of barreloid cells after an FG injection in the $\mathrm{C} 2$ barrel column. Note the large number of dendrites that spread into the adjacent barreloids (arrows). Scale bar, $100 \mu \mathrm{m}$.

high security trigeminal synapses located on the proximal dendrites (Williams et al., 1994), but it may have a significant effect on corticothalamic inputs that share the same dendritic segments. The interplay of corticothalamic and nRT inputs in distal dendrites might have a subtle but decisive role in the timing of relay cell discharges.

\section{REFERENCES}

Armstrong-James M, Callahan CA. (1991) Thalamo-cortical processing of vibrissal information in the rat. II. Spatiotemporal convergence in the thalamic ventroposterior medial nucleus (VPM) and its relevance to generation of receptive fields of S1 cortical "barrel" neurons. J Comp Neurol 303:211-224.

Bal T, von Krosigk M, McCormick DA (1990) Role of the ferret perigeniculate nucleus in the generation of synchronized oscillations in vitro. J Physiol (Lond) 483:665-685.

Brumberg JC, Pinto DJ, Simons DJ (1996) Spatial gradients of inhibitory summation in the rat whisker barrel system. J Neurophysiol 76:130-140.

Chiaia NL, Rhoades RW, Fish SE, Killackey HP (1991) Thalamic processing of vibrissal information in the rat. II. Morphological and functional properties of medial ventral posterior nucleus and posterior nucleus neurons. J Comp Neurol 314:217-236.

Cox C, Huguenard JR, Prince DA (1996) Heterogenous axonal arborizations of rat thalamic reticular neurons in the ventrobasal nucleus. J Comp Neurol 366:416-430.

Crabtree JW, Collingridge GL, Isaac TR (1998) A new intrathalamic pathway linking modality-related nuclei in the dorsal thalamus. Nat Neurosci 1:389-394.

Cucchiaro JB, Uhlrich DJ, Sherman SM (1991) Electron-microscopic analysis of synaptic input from the perigeniculate nucleus to the A-laminae of the lateral geniculate nucleus in cats. J Comp Neurol 310:316-336.

De Biasi S, Frassoni C, Spreafico R. (1988) The intrinsic organization of the ventroposterolateral nucleus and related reticular thalamic nucleus of the rat: a double-labeling ultrastructural investigation with $\gamma$-aminobutyric acid immunogold staining and lectin-conjugated horseradish peroxidase. Somatosens Mot Res 5:187-203.

Diamond ME, Armstrong-James M, Ebner FF (1992) Somatic sensory responses in the rostral sector of the posterior group and in the ventral posterior medial nucleus (VPM) of the rat thalamus. J Comp Neurol 318:462-476.

Freidberg MH, Lee SM, Ebner FF (1999) Modulation of receptive field properties of thalamic somatosensory neurons by the depth of anesthesia. J Neurophysiol 81:2243-2252.

Hartings JA, Simons DJ (2000) Inhibition suppresses transmission of tonic vibrissa-evoked activity in the rat ventrobasal thalamus. J Neurosci $20: 1-5$.

Hoogland PV, Welker E,. Van der Loos H (1987) Organization of the projections from barrel cortex to thalamus in mice studied with Phaseolus vulgaris-leucoagglutinin and HRP. Exp Brain Res 68:73-87.

Land PW, Buffer SA, Yaskoski JD (1995) Barreloids in adult rat thalamus: three-dimensional architecture and relationship to somatosensory cortical barrels. J Comp Neurol 355:573-588.

Lee SM, Friedberg MH, Ebner FF (1994) The role of GABA-mediated inhibition in the rat ventral posterior medial thalamus. I. Assessment of receptive field changes following thalamic reticular nucleus lesions. J Neurophysiol 71:1702-1713.

Liu XB, Warren RA, Jones EG (1995) Synaptic distribution of afferents from reticular nucleus in ventroposterior nucleus of cat thalamus. J Comp Neurol 352:187-202.

Ohara P, Havton L (1994) Dendritic architecture of rat somatosensory thalamocortical projection neurons. J Comp Neurol 341:159-171.

Peschanski M, Ralston HJ, Roudier F (1983) Reticularis thalami afferents to ventrobasal complex of the rat thalamus: an electron microscopic study. Brain Res 270:325-329.

Pierret T, Lavallée P, Deschênes M (2000) Parallel streams for the relay of vibrissal information through thalamic barreloids. J Neurosci 20:7455-7462.

Pinault D (1996) A novel single-cell staining procedure performed in vivo under electrophysiological control: morpho-functional features of juxtacellularly labeled thalamic cells and other central neurons with biocytin or Neurobiotin. J Neurosci Methods 65:113-136.

Pinault D, Deschênes M (1998a) Anatomical evidence for a mechanism of lateral inhibition in the rat thalamus. Eur J Neurosci 10:3462-3469.

Pinault D, Deschênes M (1998b) Projection and innervation patterns of individual thalamic reticular axons in the thalamus of the adult rat: a three-dimensional, graphic, and morphometric analysis. J Comp Neurol: 391:180-203.

Scheibel ME, Scheibel AB (1966) The organization of the nucleus reticularis thalami: a Golgi study. Brain Res 1:43-62.

Shosaku H (1986) Cross-correlation analysis of a recurrent inhibitory circuit in the rat thalamus. J Neurophysiol 55:1030-1043.

Shosaku H, Kayama Y, Sumitomo I (1984) Somatotopic organization in the rat thalamic reticular nucleus. Brain Res 311:57-63.

Simons DJ, Carvell GE (1989) Thalamocortical response transformation in the rat vibrissa/barrel system. J Neurophysiol 61:311-330.

Steriade M, Deschênes M, Domich L, Mulle C (1985) Abolition of spindle oscillations in thalamic neurons disconnected from nucleus reticularis thalami. J Neurophysiol 54:1473-1497.

Veinante P, Deschênes M (1999) Single-and multi-whisker channels in the ascending projections from the principal trigeminal nucleus in the rat. J Neurosci 19:5085-5095.

Warren RA, Jones EG (1997) Maturation of neuronal form and function in a mouse thalamo-cortical circuit. J Neurosci 17:277-295.

Williams MN, Zahm DS, Jacquin MF (1994) Differential foci and synaptic organization of the principal and spinal trigeminal projections to the thalamus in the rat. Eur J Neurosci 6:429-453.

Zantua JB, Wasserstrom JP, Arends JJ, Jacquin MF, Woolsey TA (1996) Postnatal development of mouse "whisker" thalamus: ventroposterior medial nucleus (VPM), barreloids, and their thalamocortical relay neurons. Somatosens Mot Res 13:307-322. 